\title{
Synthesis and optical properties of europium doped zinc silicate prepared using low cost solid state reaction method
}

\begin{abstract}
This paper presents a study on synthesis and optical properties of $\mathrm{Zn} 2 \mathrm{SiO} 4: 1 \mathrm{wt} \% \mathrm{Eu} 3+$ at different heat treatments. The objective of the research is to synthesize $\mathrm{Zn} 2 \mathrm{SiO} 4: 1 \mathrm{wt} \% \mathrm{Eu} 3+$ phosphor by using low cost solid state reaction method with recycled waste bottle glasses as the silicate source. The X-ray diffraction results showed that the prepared Zn2SiO4:1 wt\% Eu3+ phosphors have a sharp diffraction peak as the heat treatment temperatures were increased from 600 to $1000{ }^{\circ} \mathrm{C}$. Furthermore, the morphology from the Field emission scanning electron microscope analysis were shown the formation of well crystalline samples with dense packed grains due to the increment of heat treatment temperatures. Fourier transform infrared spectra has confirmed the present elements in $\mathrm{Zn} 2 \mathrm{SiO} 4: 1 \mathrm{wt} \% \mathrm{Eu} 3+$ phosphors while the narrow width of Raman line spectra were observed at temperatures ranging from 700 to $1000{ }^{\circ} \mathrm{C}$ indicates good homogeneity and crystallinity of synthesized powders. In addition, the energy band gap of europium doped zinc silicate increased dramatically up to $3.62 \mathrm{eV}$ at temperature of $1000{ }^{\circ} \mathrm{C}$. Photoluminescence measurements has also exhibited the red emission corresponding to the 5D0 $\ddot{Y}$ 7F2 (600 nm) when viewed under blue excitation.
\end{abstract}

Keyword: $\mathrm{Zn} 2 \mathrm{SiO} 4: 1 \mathrm{wt} \% \mathrm{Eu} 3+$; Low cost solid state reaction method; Heat treatment 